\title{
A Horizontal Competition-Cooperation Game of Technological Innovation in an Automobile Cluster Supply Chain
}

\author{
Ying Fu $\mathbb{D}^{\circ}$, Xiangmei Wang, Ying Tang $\mathbb{D}^{\mathbb{C}}$, Wei Li, Zheyu Gong, and Wenxuan Zhang \\ College of Logistics and Transportation, Central South University of Forestry and Technology, Changsha 410004, China \\ Correspondence should be addressed to Ying Tang; 20201100288@csuft.edu.cn
}

Received 17 December 2021; Revised 28 December 2021; Accepted 3 January 2022; Published 25 January 2022

Academic Editor: Tongguang $\mathrm{Ni}$

Copyright ( $) 2022$ Ying Fu et al. This is an open access article distributed under the Creative Commons Attribution License, which permits unrestricted use, distribution, and reproduction in any medium, provided the original work is properly cited.

\begin{abstract}
The horizontal competition-cooperation game of technological innovation in a two-stage automobile cluster supply chain composed of a duopoly of automobile manufacturers and a single automobile dealer is studied. The four game models are constructed based on the relationship of horizontal competition cooperation between automobile manufacturers and research and development (R\&D) mode, and each game model gives the optimal price decision and optimal technical content decision of new products when the automobile manufacturer and automobile dealer maximise their profits. By comparing the equilibrium results of each game model and conducting numerical simulation analysis, we reveal the effects of the competition-cooperation relationship and R\&D mode on supply chain decision-making. The results show the following: (1) A fully cooperative innovation strategy can maximise the total profit of automobile manufacturers, but it will reduce the profit of the automobile dealer. (2) When the horizontal competition is not fierce and the consumption preference for technical content is weak, innovation strategy of competition cooperation (competition but cooperative R\&D) can enable the automobile dealer to obtain the maximum profit. (3) Market preference for the technological content of automotive products accrues greater potential benefits to the whole supply chain channel.
\end{abstract}

\section{Introduction}

In the contemporary knowledge economy and information revolution, technological innovation has become a key factor in enterprise development. That enterprises improve the technical content of new products through $\mathrm{R} \& \mathrm{D}$ activities is an inevitable choice for improving supply chain game capabilities. Under the background of increased homogenisation of automobile products, technological innovation is also driver of development in such enterprises; therefore, automotive enterprises must continuously engage in technological innovation to improve the competitiveness of the industry. The cluster mode of a supply chain can induce more convenient conditions for technological innovation in the automobile industry. In the operational environment of the cluster supply chain, an atmosphere of competition and cooperation prevails: supply chain members adopt cooperative innovation to cope with environmental pressure, but they will also compete in the final product market for the maximisation of their own interests; for example, GAC and SAIC jointly develop core technologies but compete in the final product market. Automobile enterprises conduct horizontal cooperation in $\mathrm{R} \& \mathrm{D}$ of key technologies to stimulate market demand, creating large economic and synergistic benefits. Obviously, the problem of choosing technological innovation strategies in automobile cluster supply chain is essentially a game problem that constantly meets and stimulates consumer demand to seek the equilibrium of interests, and the competition-cooperation game of supply chain members and the choice of R\&D mode have an important influence on the solution of the above problem. This paper mainly provides a reasonable solution path for the coordination of the interests of all parties in the game, and also provides theoretical basis and technical support for automobile enterprise managers to boost profit and innovate management decisions, so as to improve the competitiveness of our country's automobile industry clusters. 
The remainder of this paper is organized as follows: Section 2 introduces related work. Section 3 raises research question and makes model assumptions. Section 4 constructs four game models of technological innovation and proposes the equilibrium strategy in different game situations. The analysis of calculation examples and numerical simulation is discussed in Section 5. Finally, Section 6 summarises the paper.

\section{Related Work}

At present, the research into supply chain technological innovation is relatively abundant, but it mainly focuses on vertical cooperation and seldom studies from the perspective of competition cooperation, and it involves less research on competition and cooperation game in the automotive supply chain. The research on the cooperative innovation of supply chain mainly focuses on the importance of cooperation, cooperation model, mode selection, benefit distribution, and so on. In terms of the importance, Du et al. [1] analysed the importance of cooperative investment contract between suppliers and manufacturers to sustainable innovation through a Stackelberg Game model. Lu et al. [2] studied the technological innovation decision-making problem of the supply chain by using the method of competition and cooperation. The fundamental motivation for enterprises to participate in technological innovation cooperation is to obtain more benefits from the cooperation. Therefore, the distribution of benefits in cooperative innovation has attracted the attention of scholars. Yoon and Jeong [3] explored the problem of maximising personal profits and total profits in the reverse supply chain from the perspective of profit distribution. Zhang [4] used the Shapley value method to propose a reasonable income distribution system for collaborative innovation in the supply chain. In terms of mode selection, Wang [5] studied the selection of vertical technological innovation mode of new products in the supply chain. Mu et al. [6] studied technological innovation in a two-stage supply chain on an e-commerce sales channel under different cooperation modes. Wei and Wang [7] used differential game methods to analyse the technological innovation of manufacturers and suppliers in terms of carbon emission reduction. The above studies have studied the longitudinal technological innovation of the supply chain from different aspects, but the research on the technological innovation from the perspective of the automotive industry is still insufficient. Most scholars' research on technological innovation of automotive supply chain focuses on its influencing factors and internal mechanisms and mainly adopts methodologies such as system dynamics and game theory. For example, Li et al. [8] used system dynamics to analyse the influencing factors of the technological innovation capability of the automobile industry. Li et al. [9] used a three-stage dynamic game model to explore the relationship between technology diffusion, innovation performance, and technology research and development in the automotive industry. Deng [10] used game theory to explore the internal mechanism of technological innovation in the automobile industry cluster. Li et al. [11] established an evolutionary game model of cooperative innovation between automobile manufacturer and battery company. It can be seen that the research on the technological innovation of the automotive supply chain seldom explores the horizontal game of technological innovation cooperation between manufacturers, and the research on the competition-cooperation relationship between enterprises is relatively lacking.

Research on horizontal competition-cooperation games involving technological innovation in supply chains mainly focuses on price and production competition, but it rarely considers the technical content of new products. Liu and Feng [12] studied "Price-Greenness" competition in a horizontal competitive game. Seyedhosseini et al. [13] proposed a new competitive demand that is price dependent for a two-stage competitive supply chain composed of a monopoly manufacturer and two duopoly retailers. Hong and Naihan [14] discussed the production and price decisions of two logistics suppliers by using the Cournot competitive model and the Bertrand competition model. Li et al. [15] built two price game models of horizontal recyclers. Mai et al. [16] constructed a dynamic Cournot model based on price competition for duopoly manufacturers. A few scholars have considered the influence of technical content of products. For example, Hu et al. [17] analysed the game problem regarding optimal technical content of duopoly enterprises with heterogeneous products. Chu [18] assessed the impact of technical content of product on channel decision by using game theory, but he focused on the improvement mechanism of technical content of product and seldom considered the combined effect of price and technical output of the product. The above research mainly discusses the horizontal competition and cooperation game problem from the aspects of price competition, green degree competition, output competition, etc. However, the research involving "price-technology content of new product" competition is still insufficient.

In summary, scholars' research on technological innovation of supply chain mostly considers vertical cooperation, production competition, and price competition; however, it does not involve competition in terms of the technical content of new products. In addition, a few studies take the automobile industry as an example to study the horizontal competition-cooperation game of technological innovation. In view of the deficiencies in the existing literature, we discuss the game equilibrium strategy of profit maximisation between two automobile manufacturers and automobile dealer in the process of horizontal competition cooperation in technological innovation under different cases from the perspective of balance of interests. It provides some theoretical support for the stakeholders along the automotive supply chain to meet the market demand and seek the balance of interests in the horizontal competition-cooperation game of technological innovation.

\section{Problem Description and Assumption}

3.1. Description. We studied the horizontal competitioncooperation game of technological innovation in the two- 
stage supply chain of automobile industry cluster composed of a duopoly of automobile manufacturers $M_{i}(i=1,2)$ and a single automobile dealer $R$. Two automobile manufacturers produce homogeneous but alternative products, which are different in terms of technical content due to their different levels of technological innovation. Since the horizontal cooperation mode is a form of joint participation in technological innovation and cooperation for enterprises in the same industry [19], therefore, whole automobile manufacturers can develop new products through technological innovation to promote the realisation of the market for new products. Automobile manufacturers sell products to an automobile dealer at price $\omega_{i}$, and then the automobile dealer sells products to the consumer at price $p_{i}$; lastly, consumers determine the demand for product $i$ according to its price $\omega_{i}, p_{i}$, and technical content $t_{i}$. The process is displayed in Figure 1.

In this supply chain model, there is horizontal competition cooperation between two automobile manufacturers. In horizontal competition, two automobile manufacturers pursue maximisation of their own interests. Two automobile manufacturers pursue maximisation of overall income in horizontal cooperation. Meanwhile, there are two modes of R\&D: cooperative and independent.

Consumers have demand preference when buying technologically innovative products, and they have higher rigid demand for products with high technical content. Both products have different technical contents because of the difference in technological innovation ability of enterprises, and consumers exactly perceive the difference of products through the difference in technical content of products; therefore, enterprises can affect consumer demand preference for products according to $p_{i}$ and $t_{i}$. In addition, the high similarity of new products developed jointly leads to the reduction of consumer perception of the difference between the two products and the increase of substitutability. Therefore, the competition between products is more intense. The four game equilibrium strategies are developed based on the horizontal competition-cooperation relationship and R\&D mode between two automobile manufacturers (Figure 2).

In Figure 2, OL is an Innovation Strategy of Pure Competition and CJ is an Innovation Strategy of Full Cooperation. CL and OJ are Innovation Strategies of Competition Cooperation, they indicate that there is a cooperative relationship between the two automobile manufacturers but independent $\mathrm{R} \& \mathrm{D}$, or there is a competitive relationship between the two automobile manufacturers but cooperative $\mathrm{R} \& \mathrm{D}$.

3.2. Symbol Description. The meaning of each variable of the game model is shown in Table 1.

\subsection{Supplementary Premise}

Assumption 1. In the automotive cluster supply chain, there are two dominant automobile manufacturers upstream in a duopoly market that has similar technological strength and equal status; there is a big $M_{i}(i=1,2)$ automobile dealer $R$ downstream. The two manufacturers cooperate in technological innovation to develop and produce new products which will be sold to the automobile dealer at price $\omega_{i}$.

Assumption 2. The parameter $\lambda(0<\lambda<1)$ is the degree of product substitution, namely, competition intensity. It reflects the substitution effect of another product when the price of one product changes, $\lambda \longrightarrow 0$ indicates that the products are irreplaceable, and $\lambda \longrightarrow 1$ indicates that the products are completely replaceable. At the same time, the larger $\lambda$, the more intense the competition between two automobile manufacturers.

Assumption 3. The production cost of $M_{i}$ can be reduced after technological innovation, and the amount of cost reduction $x_{i}$ can also represent the level of technological innovation; $\beta_{i}=1$ refers to coefficient of technology spillover between two enterprises, which is affected by some factors such as knowledge transmission ability and communication ability between supply chain enterprises. Under normal circumstances, $\beta \in[0,1]$, and $\beta=1$ when the two parties cooperate in $\mathrm{R} \& \mathrm{D}$, because the enterprise will unreservedly contribute its own technological know-how to cooperative innovation. The marginal cost of production of $M_{i}$ can be expressed as $c_{i}=c_{M_{i}}-x_{i}-\beta x_{j}, c_{M_{i}}>x_{i}+\beta x_{j}, i, j=1,2$.

Assumption 4. The technical content of the two products is $t_{i}\left(t_{i}>0\right)$. There is a diminishing effect of marginal return on $\mathrm{R} \& \mathrm{D}$ investment of new products, so it can be written as $I_{i}=(1 / 2) t_{i}^{2}$. In the case of independent $\mathrm{R} \& \mathrm{D}$, all $\mathrm{R} \& \mathrm{D}$ costs shall be borne by $M_{1}$ and $M_{2}$ alone; in the case of cooperative $\mathrm{R} \& \mathrm{D}$, the two enterprises jointly discuss the total investment of innovation which is $I_{i}=(1 / 2) t_{0}^{2}$, the share borne by $M_{1}$ is $\theta$, and the share borne by $M_{2}$ is $(1-\theta)$.

3.4. Demand Function Construction. Technological innovation comes from the pull of market demand, and enterprises seek technological innovation under the guidance of market demand [20]. In terms of model expression, demand function is the extremely important part of enterprise profit structure. The inverse demand function is defined as $p_{i}=a-q_{i}-\lambda q_{j}(i, j \in\{1,2\}, i \neq j)$, where $a$ is the basic market potential. Without loss of generality, when there is competition in price and technical content of new products, the demand function [7] is as follows: $q_{j}=a-(1 / 1-\lambda) p_{i}+$ $(\lambda / 1-\lambda) p_{j}+\mu\left((1 / 1-\lambda) t_{i}-(\lambda / 1-\lambda) t_{j}\right), a>c_{1}+c_{2}$. The two manufacturers can choose to develop either jointly or independently in terms of new key technologies for development of new products. Cooperative R\&D can bring about a reduction in differentiation and higher competitive intensity between products. It is assumed that $\xi$ represents the increased competitive extent caused by cooperative $R \& D$, and $0 \leq \xi \lambda<1$. The demand function is $q_{j}=$ $a-(1 / 1-\xi \lambda) p_{i}+(\xi \lambda / 1-\xi \lambda) \quad p_{j}+\mu\left((1 / 1-\xi \lambda) t_{i}-(\xi \lambda / 1-\right.$ $\left.\xi \lambda) t_{j}\right)$, where $\xi \geq 1$ means that competition is more intense because the difference between products perceived by consumers is reduced. 


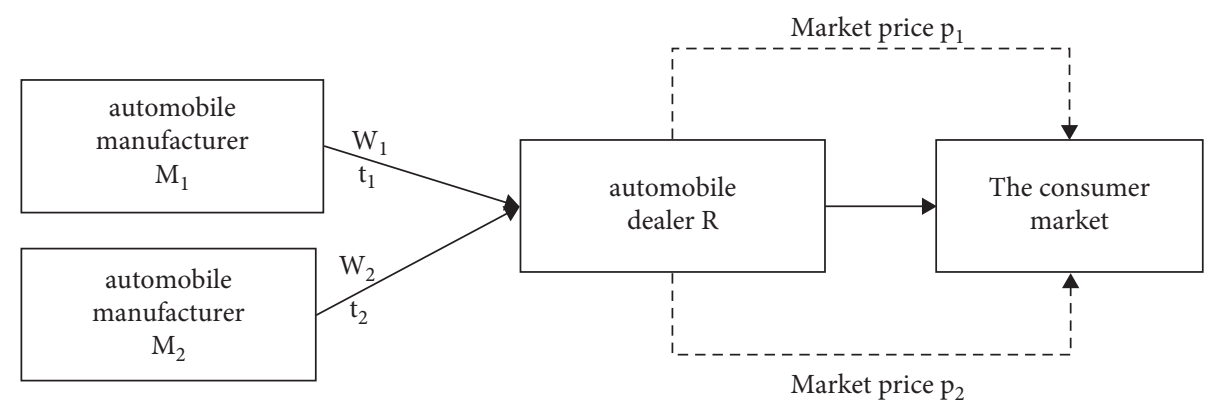

FIGURE 1: Two-stage supply chain with technological content and price competition of new products.

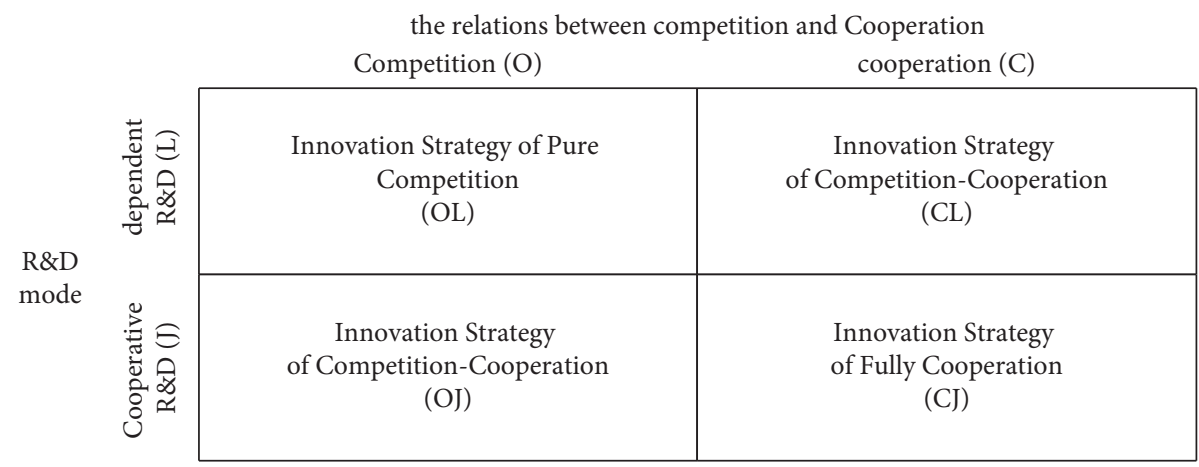

FIGURE 2: The four game equilibrium strategies.

TABLE 1: List of symbols.

\begin{tabular}{lc}
\hline Symbol & Description \\
\hline $\mathbf{i}$ & Automobile manufacturer product, $i=1,2$ \\
$\lambda$ & Alternative levels of products, namely, competition intensity $(0<\lambda<1)$ \\
$\mathbf{c}_{\mathbf{M}_{\mathbf{i}}}$ & Production cost of automobile manufacturers \\
$\mathbf{c}_{\mathbf{i}}$ & The marginal production cost of automobile manufacturers \\
$\mathbf{I}_{\mathbf{i}}$ & The R\&D investment cost of new products \\
$\mathbf{x}_{\mathbf{i}}$ & The cost reduction caused by technological innovation \\
$\beta_{\mathbf{i}}$ & Coefficient of technology spillover, $0<\beta_{i}<1$ \\
$\mathbf{t}_{\mathbf{i}}$ & Technical content of product $i, t_{i}>0$ \\
$\mathbf{t}_{0}$ & Technical content of new products in cooperation development \\
$\theta$ & Share of R\&D investment undertaken by automobile manufacturer $M_{1}$ \\
$\xi$ & The increased competitive extent caused by cooperative research and development \\
$\mu$ & Basic demand for entire automobile manufacturers, $a>0$ \\
$\mathbf{a}$ & Demand for automobile manufacturers \\
$\mathbf{q}_{\mathbf{i}}$ & Market price \\
$\mathbf{p}_{\mathbf{i}}$ & Wholesale price \\
$\omega_{\mathbf{i}}$ & The profit of automobile manufacturer \\
$\pi_{\mathbf{M}_{\mathbf{i}}}$ & The total profit of automobile manufacturers \\
$\pi_{\mathbf{M}}^{T}$ & The profit of automobile dealer \\
$\pi_{\mathbf{R}}^{\mathrm{T}}$ &
\end{tabular}

\section{Construction and Analysis of the Game Model of Technological Innovation}

According to the horizontal competition-cooperation relationship and R\&D mode between two automobile manufacturers, we constructed four game models of technological innovation.
The four game models of technological innovation, namely, four game equilibrium strategies of technological innovation, are constructed according to the different competition-cooperation relationship and $\mathrm{R} \& \mathrm{D}$ modes of two automobile manufacturers. The game model can be described as the profit expression of each member of the supply chain, which is the marginal profit multiplied by the 
demand function from which $R \& D$ investment in new products is then subtracted. When calculating the profit, the marginal profit is equal to the wholesale price minus the production cost or the market sales price minus the wholesale price; R\&D investment in new products is expressed as a quadratic function of technical content of new products; the marginal production cost of automobile manufacturers is calculated by subtracting the reduction of production cost caused by technological innovation from the production cost. The model is solved by backward induction to obtain the equilibrium strategy of each game case, corresponding to the optimal wholesale price, the optimal market price, and the optimal technical content of new products, giving the equilibrium profit of each channel member. To facilitate differentiation, “*” is used herein to represent the best decision.

4.1. Game Equilibrium Strategy of Pure Competitive Innovation $(\mathrm{OL})$. In the $\mathrm{OL}$ strategy, two automobile manufacturers have a competitive relationship and independently develop new products. The game rules are such that automobile manufacturers first decide the wholesale price of two products and the technical content of new products based on maximisation of their own profit; then the automobile dealer decides the market price of the two products. The game model is described as follows:

$$
\text { S.t. }\left\{\begin{array}{l}
\max \pi_{M_{1}}^{O L}=\left(\omega_{1}-\left(c_{M_{1}}-x_{1}-\beta x_{2}\right)\right)\left(a-\frac{p_{1}^{*}-\mu t_{1}}{1-\lambda}+\frac{\lambda\left(p_{2}^{*}-\mu t_{2}\right)}{1-\lambda}\right)-\frac{1}{2} t_{1}^{2}, \\
\max \pi_{M_{1}}^{O L}=\left(\omega_{2}-c_{2}\right)\left(a-\frac{p_{2}^{*}-\mu t_{2}}{1-\lambda}+\frac{\lambda\left(p_{1}^{*}-\mu t_{1}\right)}{1-\lambda}\right)-\frac{1}{2} t_{2}^{2}, \\
\left(p_{1}^{*}, p_{2}^{*}\right) \text { must meet the following condition: } \\
\max \pi_{R}^{O L}=\left(p_{1}-\omega_{1}\right)\left(a-\frac{p_{1}-\mu t_{1}}{1-\lambda}+\frac{\lambda\left(p_{2}-\mu t_{2}\right)}{1-\lambda}\right) \\
+\left(p_{2}-\omega_{2}\right)\left(a-\frac{p_{2}-\mu t_{2}}{1-\lambda}+\frac{\lambda\left(p_{1}-\mu t_{1}\right)}{1-\lambda}\right) .
\end{array}\right.
$$

Proposition 1. In the OL strategy, the optimal wholesale price and the optimal technical content of new products of manufacturers and the optimal market price and the optimal technical content of new products of dealer can be written as

$$
\begin{aligned}
& \omega_{i}^{O L^{*}}=\frac{a+c_{M_{i}}-x_{i}-\beta x_{j}}{2}+\frac{\mu^{2}\left(a-c_{M_{i}}+x_{i}+\beta x_{j}\right)}{8-2 \mu^{2}}, \\
& t_{i}^{O L^{*}}=\frac{\mu\left(a-c_{M_{i}}+x_{i}+\beta x_{j}\right)}{4-\mu^{2}}, \\
& p_{i}^{O L^{*}}=\frac{3 a+c_{M_{i}}-x_{i}-\beta x_{j}}{4}+\frac{3 \mu^{2}\left(a-c_{M_{i}}+x_{i}+\beta x_{j}\right)}{16-4 \mu^{2}} .
\end{aligned}
$$

Proof. By backward induction, we find the market price of automobile dealer when given the wholesale price decision and the technical content of decision $\left(\omega_{1}, t_{1}, \omega_{2}, t_{2}\right)$ of the automobile manufacturers. Firstly, taking the first-order partial derivatives of $\pi_{R}^{C J}$ with respect to $p_{1}$ and $p_{2}$, respectively, and taking the second-order derivatives, the Hessian matrix is obtained:

$$
\begin{aligned}
H & =\left[\begin{array}{cc}
\frac{\partial^{2} \pi_{R}^{O L}}{\partial p_{1}^{2}} & \frac{\partial^{2} \pi_{R}^{O L}}{\partial p_{1} p_{2}} \\
\frac{\partial^{2} \pi_{R}^{O L}}{\partial p_{2} p_{1}} & \frac{\partial^{2} \pi_{R}^{O L}}{\partial p_{2}^{2}}
\end{array}\right] \\
& =\left[\begin{array}{cc}
\frac{2}{\lambda-1} & -\frac{2 \lambda}{\lambda-1} \\
-\frac{2 \lambda}{\lambda-1} & \frac{2}{\lambda-1}
\end{array}\right] .
\end{aligned}
$$

Note that $\partial^{2} \pi_{R}^{O L} / \partial p_{1}^{2}=2 / \lambda-1<0 \quad$ when $\left|\begin{array}{cc}2 / \lambda-1 & -2 \lambda / \lambda-1 \\ -2 \lambda / \lambda-1 & 2 / \lambda-1\end{array}\right|=4(1+\lambda) / 1-\lambda>0 ; \pi_{R}^{C J}$ is a strictly concave function of $p_{i}$, so there is a unique maximal solution. Taking the first-order partial derivative of $p_{i}$ and setting it to zero gives 
$\left\{\begin{array}{l}a+\frac{p_{1}-\omega_{1}}{\lambda-1}+\frac{p_{1}-\mu t_{1}}{\lambda-1}-\frac{\lambda\left(p_{2}-\mu t_{2}\right)}{\lambda-1}-\frac{\lambda\left(p_{2}-\omega_{2}\right)}{\lambda-1}=0, \\ a+\frac{p_{2}-\omega_{2}}{\lambda-1}+\frac{p_{2}-\mu t_{2}}{\lambda-1}-\frac{\lambda\left(p_{1}-\mu t_{1}\right)}{\lambda-1}-\frac{\lambda\left(p_{1}-\omega_{1}\right)}{\lambda-1}=0 .\end{array}\right.$

According to equation (4),

$$
\left\{\begin{array}{l}
p_{1}=\frac{\omega_{1}+a+\mu t_{1}}{2} \\
p_{2}=\frac{\omega_{2}+a+\mu t_{2}}{2}
\end{array}\right.
$$

Substituting equation (5) into the profit function $\pi_{M_{1}}^{C J}$ of automobile manufacturer $M_{1}$ gives

$$
\pi_{M_{1}}^{O L}\left(w_{1}, t_{1}\right)=\left(\omega_{1}-\left(c_{M_{1}}-x_{1}-\beta x_{2}\right)\right)\left(a-\frac{\left(\omega_{1}+a+\mu t_{1} / 2\right)-\mu t_{1}}{1-\lambda}+\frac{\left(\lambda\left(\omega_{2}+a+\mu t_{2}\right) / 2\right)-\mu t_{2}}{1-\lambda}-\frac{1}{2} t_{1}^{2} .\right.
$$

Taking the first-order partial derivatives of $\pi_{M_{1}}^{O L}\left(w_{1}, t_{1}\right)$ with respect to $\omega_{1}, t_{1}$, respectively, and taking the secondorder derivatives, we obtain the Hessian matrix:

$$
\begin{aligned}
H & =\left[\begin{array}{ll}
\frac{\partial^{2} \pi_{M_{1}}^{O L}\left(\omega_{1}, t_{1}\right)}{\partial \omega_{1}^{2}} & \frac{\partial^{2} \pi_{M_{1}}^{O L}\left(\omega_{1}, t_{1}\right)}{\partial \omega_{1} t_{1}} \\
\frac{\partial^{2} \pi_{M_{1}}^{O L}\left(\omega_{1}, t_{1}\right)}{\partial t_{1} \omega_{1}} & \frac{\partial^{2} \pi_{M_{1}}^{O L}\left(\omega_{1}, t_{1}\right)}{\partial t_{1}^{2}}
\end{array}\right] \\
& =\left[\begin{array}{cc}
-1 & \frac{\mu}{2} \\
\frac{\mu}{2} & -1
\end{array}\right] .
\end{aligned}
$$

Since $\quad\left(\partial^{2} \pi_{M_{1}}^{O L}\left(\omega_{1}, t_{1}\right) / \partial \omega_{1}^{2}\right)<0 \quad$ and $\quad\left|\begin{array}{cc}-1 & \mu / 2 \\ \mu / 2 & -\theta\end{array}\right|=1-$ $\left(\mu^{2} / 4\right)>0, \pi_{M_{1}}^{O L}\left(w_{1}, t_{1}\right)$ is a strictly concave function of $\omega_{1}$ and $t_{1}$. Taking the first derivative of $\partial^{2} \pi_{M_{1}}^{O L}\left(w_{1}, t_{1}\right)$ with regard to $\omega_{1}$ and set it to zero, $\omega_{1}$ can be written as follows:

$$
\omega_{1}\left(t_{1}\right)=\frac{a+c_{M_{1}}-x_{1}-\beta x_{2}+\mu t_{1}}{2} .
$$

Substituting equation (8) into equation (6), the profit of manufacturer $M_{1}$ is as follows:

$$
\begin{aligned}
\pi_{M_{1}}^{O L}\left(t_{1}\right)= & \left(\frac{a+c_{M_{1}}-x_{1}-\beta x_{2}+\mu t_{1}}{2}-\left(c_{M_{1}}-x_{1}-\beta x_{2}\right)\right) \\
& \left(a-\frac{\left(\left(\left(a+c_{M_{1}}-x_{1}-\beta x_{2}+\mu t_{1}\right) / 2\right)+a+\mu t_{1} / 2\right)-\mu t_{1}}{1-\lambda}+\frac{\left(\lambda\left(\left(a+c_{M_{1}}-x_{1}-\beta x_{2}+\mu t_{2} / 2\right)+a+\mu t_{2}\right) / 2\right)-\mu t_{2}}{1-\lambda}-\frac{1}{2} t_{1}^{2} .\right.
\end{aligned}
$$

Setting the first derivative of equation (9) with respect to $t_{1}$ to zero, the optimal technical content of the new products is described as

$$
t_{1}^{*}=\frac{a \mu-\left(c_{M_{1}}-x_{1}-\beta x_{2}\right) \mu}{-\mu^{2}+4} .
$$

Substituting equation (10) into equation (8), the optimal wholesale price can be obtained:

$$
\omega_{1}^{*}=\frac{a+c_{M_{1}}-x_{1}-\beta x_{2}}{2}+\frac{\mu^{2}\left(a-c_{M_{1}}+x_{1}+\beta x_{2}\right)}{8-2 \mu^{2}} .
$$

By the same calculation, the optimal wholesale price and technical content of new products of automobile manufacturer $M_{i}$ are written as follows:

$$
\begin{aligned}
t_{i}^{O L^{*}} & =\frac{\mu\left(a-c_{M_{i}}+x_{i}+\beta x_{j}\right)}{4-\mu^{2}}, \\
\omega_{i}^{O L^{*}} & =\frac{a+c_{M_{i}}-x_{i}-\beta x_{j}}{2}+\frac{\mu^{2}\left(a-c_{M_{i}}+x_{i}+\beta x_{j}\right)}{8-2 \mu^{2}},
\end{aligned}
$$

$p_{i}^{O L^{*}}=\frac{3 a+c_{M_{i}}-x_{i}-\beta x_{j}}{4}+\frac{3 \mu^{2}\left(a-c_{M_{i}}+x_{i}+\beta x_{j}\right)}{16-4 \mu^{2}}$

Proposition 1 is proved.

Inference 1. In the OL strategy, the sensitive coefficient of the technical content of new products is positively correlated with technical content of new products, wholesale price, and market price. 
Proof

$$
\begin{aligned}
& \frac{\partial t_{i}^{O L^{*}}}{\partial \mu}=\frac{\left(a-c_{M_{i}}+x_{i}+\beta x_{j}\right)\left(\mu^{2}+4\right)}{\left(\mu^{2}-4\right)^{2}}>0, \\
& \frac{\partial \omega_{i}^{O L^{*}}}{\partial \mu}=\frac{\left(a-c_{M_{i}}+x_{i}+\beta x_{j}\right)\left(\mu^{3}+16 \mu\right)}{\left(2 \mu^{2}-8\right)^{2}}>0, \\
& \frac{\partial p_{i}^{O L^{*}}}{\partial \mu}=\frac{96 \mu}{\left(4 \mu^{2}-16\right)^{2}}>0 .
\end{aligned}
$$

Inference 1 indicates that the more consumers are sensitive to technical content in new products, the more likely they are to buy high-tech automobile products, which can stimulate automobile manufacturers to improve the technological content of products and also bring about higher wholesale price and market sales price.

The equilibrium profit $\pi_{M_{1}}^{O L^{*}}, \pi_{M_{2}}^{O L^{*}}$ of two automobile manufacturers and the equilibrium profit $\pi_{R}^{O L^{*}}$ of automobile dealer can be obtained by Proposition 1 and equation (1).

4.2. Game Equilibrium Strategy of Competition-Cooperation Innovation $(C L)$. In the CL strategy, the automobile manufacturers enjoy a competitive relationship but cooperate to develop new products. The game rule is such that two automobile manufacturers cooperate in $\mathrm{R} \& \mathrm{D}$ and, respectively, bear the costs thereof. They first set the common technological content $t_{0}$ of the two products based on the maximum total revenue, $M_{1}$ bears the R\&D cost in proportion $\theta$, which is $(1 / 2) \theta t_{0}^{2}$, and $M_{2}$ bears the R\&D cost in proportion $(1-\theta)$, that is, $(1 / 2)(1-\theta) t_{0}^{2}$. The two automobile manufacturers decide their wholesale price based on their maximum profit; then the automobile dealer decides their market price based on acquiring maximum profit. The game model is described as follows:

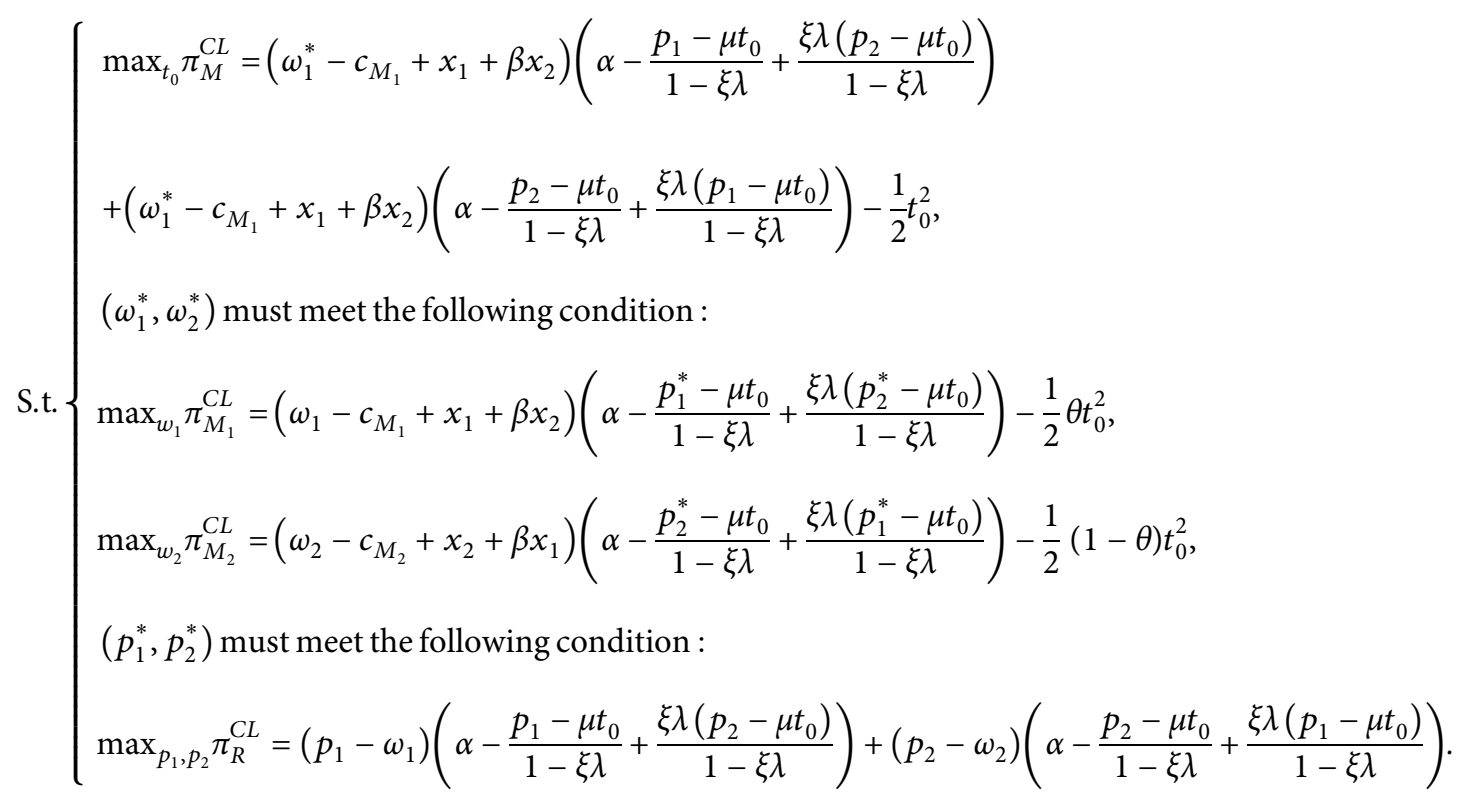

Proposition 2. In the CL strategy, the optimal wholesale price and the optimal technical content of new products of manufacturers and the optimal market price and the optimal technical content of new products of dealer are as follows:

$$
\begin{aligned}
t_{0}^{C L^{*}} & =\frac{\mu\left(a-c_{M_{i}}+x_{i}+\beta x_{j}\right)(1-\xi \lambda)}{2 \theta(2-\xi \lambda)^{2}-2 \mu^{2}(1-\xi \lambda)^{2}}-\frac{\mu\left(c_{M_{1}}-x_{1}-\beta x_{2}+c_{M_{2}}-x_{2}-\beta x_{1}\right)}{4} \\
\omega_{i}^{C L^{*}} & =\frac{\left(a-c_{M_{i}}+x_{i}+\beta x_{j}\right)(1-\xi \lambda)}{\theta(2-\xi \lambda)^{2}-\mu^{2}(1-\xi \lambda)^{2}} \\
p_{i}^{O L^{*}} & =\frac{2 a-\mu\left(c_{1}+c_{2}\right)}{4}+\frac{\left(a-c_{i}\right)(1-\xi \lambda)(1+\mu)}{2 \theta(2-\xi \lambda)^{2}-2 \mu^{2}(1-\xi \lambda)^{2}}
\end{aligned}
$$


Proposition 2 can be proved by backward induction in a manner similar to Proposition 1.

The equilibrium profits $\pi_{M_{1}}^{C L^{*}}$ and $\pi_{M_{2}}^{C L^{*}}$ of two automobile manufacturers and the equilibrium profit $\pi_{R}^{C L^{*}}$ of automobile dealer can be obtained by the combination of Proposition 2 and equation (13).

Inference 2. In the CL strategy, the improvement of technical content of new products is conducive to the increase of total profit earned by the automobile manufacturers.

Proof. Based on the above conclusions, the partial derivative of the total profit of automobile manufacturer on the technical content of new products can be obtained:

$$
\frac{\partial \pi_{M_{1}}^{C L^{*}}}{\partial t_{0}}>0, \quad \frac{\partial \pi_{M_{2}}^{C L^{*}}}{\partial t_{0}}>0 .
$$

Inference 2 indicates that the technical content of new products must be improved to maximise the total profit of automobile manufacturers. This is mainly because increasing the technical content of new products can bring about higher wholesale price and stimulate market demand, which will lead to more profits. On the one hand, the improvement of technical content requires more $R \& D$ investment costs, manufacturers' assembly costs are also higher, so the wholesale price is higher; on the other hand, consumers have a demand preference for high-tech products. The higher the technical content of the product is, the more it will be favoured by consumers, and the market demand for a product is greater under the influence of the relationship of supply and demand.

4.3. Game Equilibrium Strategy of Competition-Cooperation Innovation (OJ). The two automobile manufacturers in an OL strategy enjoy a cooperative relationship but independently develop new products. The game rule is such that the two automobile manufacturers decide their respective wholesale price and technical content of new products based on the maximum total revenue accruing to both parties, and then the automobile dealer sets the market sales price of the two products based on its maximum revenue. The game model can be described as follows:

$$
\text { S.t. }=\left\{\begin{array}{l}
\max _{t_{1}, \omega_{1}, t_{2}, \omega_{2}} \pi_{M}^{0 j}=\left(\omega_{1}-c_{M_{1}}+x_{1}+\beta x_{2}\right)\left(\alpha-\frac{p_{1}^{*}-\mu t_{1}}{1-\lambda}+\frac{\lambda\left(p_{2}^{*}-\mu t_{2}\right)}{1-\lambda}\right) \frac{t_{1}^{2}}{2} \\
+\left(\omega_{2}-c_{M_{2}}+x_{2}+\beta x_{1}\right)\left(\alpha-\frac{p_{2}^{*}-\mu t_{2}}{1-\lambda}+\frac{\lambda\left(p_{1}^{*}-\mu t_{1}\right)}{1-\lambda}\right)-\frac{t_{2}^{2}}{2}, \\
\left(p_{1}^{*}, p_{2}^{*}\right) \text { must meet the following condition : } \\
\max _{p_{1}, p_{2}} \pi_{M}^{0 j}=\left(p_{1}, p_{1}\right)\left(\alpha-\frac{p_{1}-\mu t_{1}}{1-\lambda}+\frac{\lambda\left(p_{2}-\mu t_{2}\right)}{1-\lambda}\right) \\
+\left(p_{2}, p_{2}\right)\left(\alpha-\frac{p_{2}-\mu t_{2}}{1-\lambda}+\frac{\lambda\left(p_{1}-\mu t_{1}\right)}{1-\lambda}\right),
\end{array}\right.
$$

Proposition 3. In the OJ strategy, the optimal wholesale price and the optimal technical content of new products of manufacturers and the optimal market price and the optimal technical content of new products of dealer are as follows:

$$
\begin{aligned}
& t_{i}^{O J^{*}}=-\frac{\mu\left(a-c_{M_{i}}+x_{i}+\beta x_{j}\right)(1+\lambda)}{\mu^{2}+\lambda \mu^{2}-4}, \\
& \omega_{i}^{O J^{*}}=\frac{a+c_{M_{i}}-x_{i}-\beta x_{j}}{2}-\frac{\mu^{2}\left(a-c_{M_{i}}+x_{i}+\beta x_{j}\right)(1+\lambda)}{2\left(\mu^{2}+\mu^{2} \lambda-4\right)}, \\
& p^{O J^{*}}=\frac{3 a+c_{M_{i}}-x_{i}-\beta x_{j}}{4}-\frac{3 \mu^{2}\left(a-c_{M_{i}}+x_{i}+\beta x_{j}\right)(1+\lambda)}{4} .
\end{aligned}
$$

Proposition 3 can be proved by backward induction in a manner similar to Proposition 1.

Inference 3. In OJ strategy, the inhibitory effect of competitive intensity on wholesale price is greater than that on market price.

Proof. Since $\partial \omega^{O J^{*}} / \partial \lambda=\left(\left(-\mu^{2} a-c_{M_{i}}+x_{i}+\beta x_{j} t(\lambda+1) n-\right.\right.$ $\left.q \mu^{2} h\left(a-c_{M_{i}}+x_{i}+\beta x_{j}\right)\left(\lambda \mu^{2}+\mu^{2}-4\right) / 2\right)<0, \partial p^{O J^{*}} / \partial \lambda=$ $\left(\left(-3 \mu^{2}\left(a-c_{M_{i}}+x_{i}+\beta x_{j}\right)\right) / 4\right)<0$, so competitive intensity has a restraining effect on wholesale price and market price. At the same time, $\left(\partial \omega^{O J^{*}} / \partial \lambda\right)-\left(\partial p^{O J^{*}} / \partial \lambda\right)=$ $\left(u^{2}\left(a-c_{i}\right)\left[3-2\left(\lambda \mu^{2}+\mu^{2}-4\right)-2 \mu^{2}(\lambda+1)\right] / 4\right)>0 \quad$ when $0<\lambda<1$, we can obtain $\left(\partial \omega^{O J^{*}} / \partial \lambda\right)-\left(\partial p^{O J^{*}} / \partial \lambda\right)>0$; thus, inference 3 is proved. 
Inference 3 shows that the wholesale price and market price will decrease with the increase of competitive intensity in the OJ strategy. Therefore, the two automobile manufacturers should take measures to reduce the competitive intensity between them to alleviate the overall loss of profit caused by intensified competition.

Combining Proposition 3 and equation (16), the equilibrium profit $\pi_{M_{1}}^{O J^{*}}$ and $\pi_{M_{2}}^{O J^{*}}$ of two automobile manufacturers and the equilibrium profit $\pi_{R}^{O J^{*}}$ of automobile dealer can be obtained.
4.4. Game Equilibrium Strategy of Fully Cooperative Innovation $(C J)$. In the $\mathrm{CJ}$ strategy, two automobile manufacturers enjoy a cooperative relationship and cooperate to develop new products. The game rule is such that the two automobile manufacturers share the $R \& D$ costs of new products. First, the common technical content $t_{0}$ and their respective wholesales are determined based on the maximum total revenue of both parties, and then the automobile dealer determines the market selling price of new products based on their own profits. The game model is described as follows:

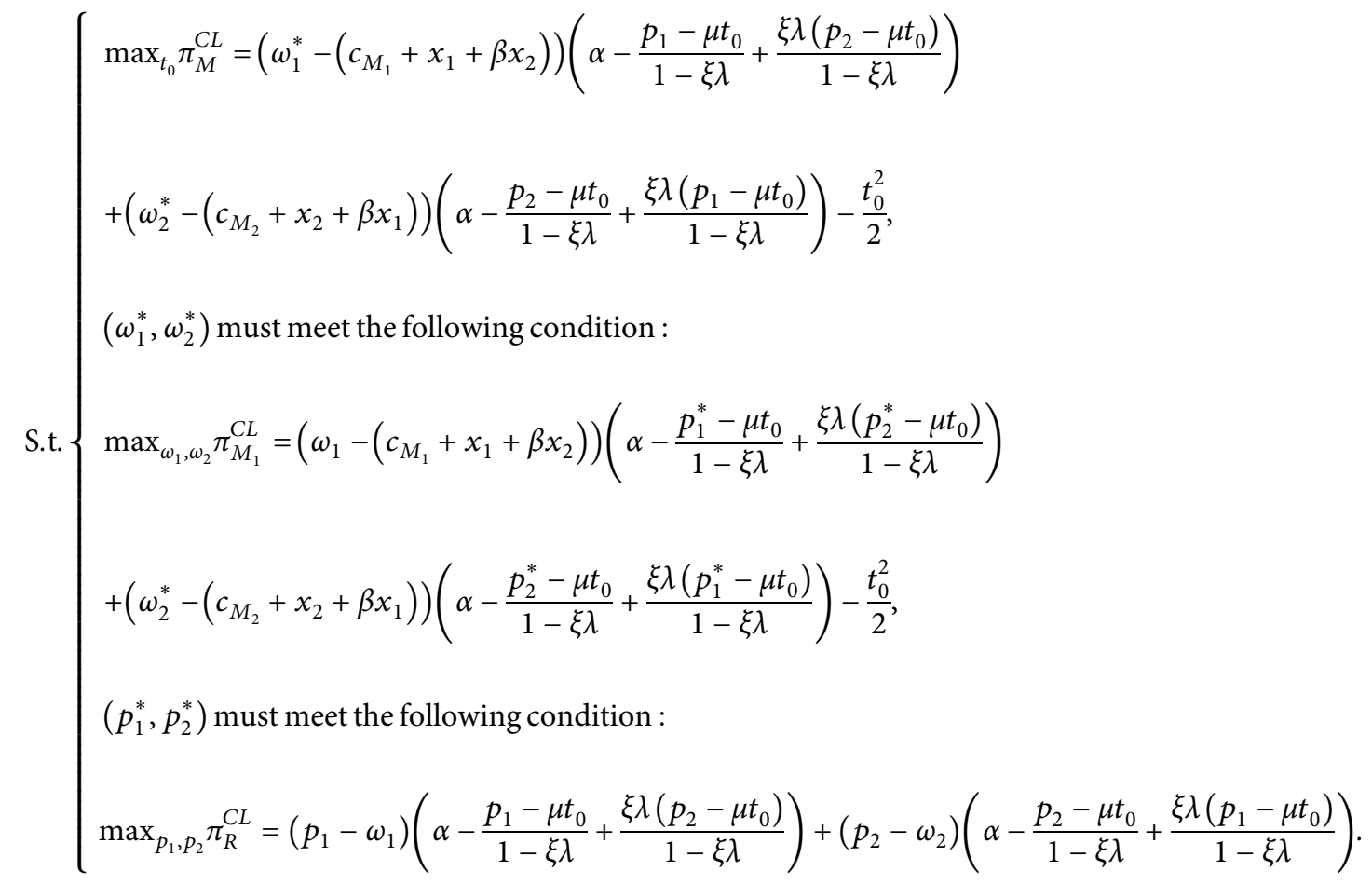

Proposition 4. In the CJ strategy, the optimal wholesale price and the optimal technical content of new products of manufacturers and the optimal market price and the optimal technical content of new products of dealer are as follows:

$$
\begin{aligned}
t_{0}^{C J^{*}} & =-\frac{\mu\left(c_{M_{1}}-x_{1}-\beta x_{2}+c_{M_{2}}-x_{2}-\beta x_{1}\right)}{2}, \\
\omega_{i}^{C J^{*}} & =\frac{a+c_{M_{i}}-x_{i}-\beta x_{j}}{2}-\frac{\mu^{2}\left(c_{M_{1}}-x_{1}-\beta x_{2}+c_{M_{2}}-x_{2}-\beta x_{1}\right)}{4}, \\
p_{i}^{C J^{*}} & =\frac{3 a+c_{M_{i}}-x_{i}-\beta x_{j}}{4}-\frac{3 \mu^{2}\left(c_{M_{1}}-x_{1}-\beta x_{2}+c_{M_{2}}-x_{2}-\beta x_{1}\right)}{8} .
\end{aligned}
$$

By backward induction, the proof of Proposition 4 is akin to that of Proposition 1.
Inference 4. The demand of automobile manufacturers will increase with the technical content of new products. 
Proof

$$
q^{C J}=a-\frac{1}{1-\lambda} p_{i}^{C J}+\frac{\lambda}{1-\lambda} p_{j}^{C J}+\mu\left(\frac{1}{1-\lambda} t_{i}^{C J}+\frac{\lambda}{1-\lambda} t_{j}^{C J}\right),
$$

$\frac{\partial q_{i}^{C J}}{\partial t_{i}}=\frac{\mu}{(1-\lambda)}>0$

$\frac{\partial q_{i}^{C J}}{\partial t_{j}}=\frac{\lambda}{1-\lambda}>0$

Inference 4 implies that the technical content of new products is positively correlated with consumer demand preference. Consumers perceive the difference of products by the technical content of products and tend to buy automobile products with high technical content at an acceptable price, so automobile manufacturers can increase consumer demand by improving the technical content of their new products.

Combining Proposition 4 and equation (18), the equilibrium profit $\pi_{M}^{C J^{*}}, \pi_{M_{2}}^{C J^{*}}$ of two automobile manufacturers and the equilibrium profit $\pi_{R}^{C J^{*}}$ of automobile dealer can be obtained by solving the equation.

\subsection{Comparative Analysis of the Equilibrium Results of the Game of Technological Innovation}

Proposition 5. Comparing the technical content of new products under the equilibrium state of different games, we can see as follows: (1) $t_{i}^{O J}>t_{i}^{O L}>t_{0}^{C J} \backslash$ and (2) $t_{0}^{C L}>t_{0}^{C J}$.

Proof. $t_{i}^{O L}-t_{0}^{C J}=\left(\left(\mu\left(a-c_{i}\right)\right) /\left(4-\mu^{2}\right)\right)+\left(\left(\mu\left(c_{1}+c_{2}\right)\right) / 2\right)>$ 0 , namely, $t_{i}^{O L}>t_{i}^{C J} t_{i}^{O L}-t_{i}^{O J}=\left(\left(\mu\left(a-c_{i}\right)\right) /\left(4-\mu^{2}\right)\right)-$ $\left(\left(\mu\left(a-c_{i}\right) \quad(1+\lambda)\right) /\left(4-\mu^{2}-\lambda \mu^{2}\right)\right)>0$, namely, $t_{i}^{O L}>t_{i}^{O J}$; $t_{i}^{C L}-t_{i}^{C J}=\left(\left(\mu\left(a-c_{i}\right)(1-\xi \lambda)\right)\right) / \quad\left(2 \theta(2-\xi \lambda)^{2}-2 \mu^{2}(1-\right.$ $\left.\xi \lambda)^{2}\right)+\left(\mu\left(c_{1}+c_{2}\right)\right) / 4>0$, namely, $t_{i}^{C L}>t_{i}^{C J}$.

In the same way, other inequalities can be proved. From Proposition 5, we can see that for the technical content of new products, OJ is greater than OL and CJ, and CL is bigger than CJ. This is because the competition and cooperation environment is more conducive to stimulating enthusiasm towards R\&D between horizontal enterprises, thus continuously improving the efficiency of R\&D and the technical level of new products. In addition, due to consumer preference for technological content, enterprises will also be forced to improve their core competitiveness by improving the technical content of new products in independent $\mathrm{R} \& \mathrm{D}$ to win greater market share.

Proposition 6. Comparing the wholesale price decision in the equilibrium state of different games, it can be known that (1) $\omega_{i}^{O J}>\omega_{i}^{O L}$ and $(2) \omega_{i}^{C J}>\omega_{i}^{O L}>\omega_{i}^{C L}$.

Proof. $\omega_{i}^{O L}-\omega_{i}^{O J}=\left(\mu^{2}\left(a-c_{i}\right)\right) /\left(8-2 \mu^{2}\right)-\left(\left(\mu^{2} \quad\left(a-c_{i}\right)\right.\right.$ $(1+\lambda))) /\left(8-2 \mu^{2}-2 \lambda \mu^{2}\right)<0$, namely, $\omega_{i}^{O J}>\omega_{i}^{O L} ; \quad \omega_{i}^{C J}-$ $\omega_{i}^{C L}=\left(\left(6 a+2 c_{i}+3 \mu^{2}\left(c_{1}+c_{2}\right)\right) / 8\right)+\left(\left(a-c_{1}\right)(1-\xi \lambda) / \theta\right.$ $\left.(2-\xi \lambda)^{2}-\mu^{2}(1-\xi \lambda)^{2}\right)>0$, namely, $\omega_{i}^{C J}>\omega_{i}^{C L}$.
Similarly, other inequalities can be proved. According to Proposition 6, the game equilibrium strategy of fully cooperative innovation can allow the two automobile manufacturers obtain higher wholesale price. The wholesale price of OJ is higher than that of OL, indicating that the cooperative relationship can result in a higher wholesale price than the competitive relationship when two automobile manufacturers undertake independent $R \& D$, because in a competitive environment, companies tend to adopt lowprice strategies to win a greater market share.

Proposition 7. Comparing the market price decision under the equilibrium state of different games, we find that (1) $p_{i}^{C J}>p_{i}^{C L}, p_{i}^{O J}, p_{i}^{O L}$ and $(2) p_{i}^{O L}>p_{i}^{O J}$.

Proof. $p_{i}^{C J}-p_{i}^{O J}=\left(3 \mu^{2}\left(a-c_{i}\right)(1+\lambda) / 4\right)-\left(3 \mu^{2}\left(c_{1}+c_{2}\right) / 8\right)>$ $\left(3 a+c_{i} / 4\right)-\left(3 a+c_{i} / 4\right)=0$, namely, $p_{i}^{C J}>p_{i}^{O J} ; \quad p_{i}^{O L}-p_{i}^{O J}=$ $\left(3 \mu^{2}\left(a-c_{i}\right) / 16-4 \mu^{2}\right)+\left(3 \mu^{2}\left(a-c_{i}\right)(1+\lambda) / 4\right)>0$, namely, $p_{i}^{O L}>p_{i}^{O J}$. Other inequalities can be proved in the same way. According to Proposition 7, the game equilibrium strategy of fully cooperative innovation results in the highest market price, because a cooperative relationship weakens price competition, and joint $\mathrm{R} \& \mathrm{D}$ can yield higher technical content in new products; thus, the automobile dealer can obtain a higher market sales price than when in a competitive relationship.

Considering the complexity of game model, it is difficult to compare the total profit of an automobile manufacturer and the profit of the automobile dealer in different game scenarios through mathematical derivation alone. This study will be conducted using sample calculations and numerical simulation analysis in the following section.

\section{Examples and Numerical Simulation Analysis}

The previous content describes an analysis of the equilibrium solution of each member in the four game situations: the further to analyse the influence of the main factors influencing the model on the supply chain decision value, we used MATLAB ${ }^{\mathrm{TM}}$ software to conduct sample calculations and numerical simulation analysis, thus providing insight into technological innovation cooperation and recommendations for decision-making. The parameters used in this section are established [12] and salient automobile market data:

$$
\begin{aligned}
\mu & =0.9, \\
a & =2, \\
\lambda & =0.3, \\
\xi & =2, \\
\theta & =0.6, \\
\beta & =0.4, \\
x_{i} & =0.4, \\
c_{M_{1}} & =0.5, \\
c_{M_{2}} & =0.5 .
\end{aligned}
$$


5.1. Profit Comparison under Different Game Equilibrium Strategies of Technology Innovation. Four types of game equilibrium profits can be obtained by substituting the above parameters into the model, as shown in Table 2.

It can be seen from Table 2 that the game equilibrium strategy of fully cooperative innovation enables two automobile manufacturers to maximise their prices to maximise profits but will damage the interests of automobile dealers. For automobile dealers, $\mathrm{CL}$ is better than $\mathrm{CJ}$, and $\mathrm{OL}$ is better than OJ, because horizontal competition will stimulate automobile manufacturers to innovate to gain a competitive advantage, thus maximising the profit of the automobile dealer.

\subsection{Influence of the Sensitivity Coefficient of New Product} Technical Content on the Equilibrium Solution. In this section, we describe analysis of the influence of the sensitivity coefficient of the technical content of new products on wholesale price, market price, total profit accruing to the automobile manufacturers, and those of the automobile dealer (Figures 3-7).

Figure 3 shows that as the sensitivity coefficient of new product technical content increases, the technical content of new product of all strategies increases. When $0<\mu<0.8$, $\mathrm{CL}>\mathrm{OJ}>\mathrm{OL}>\mathrm{CJ}$; when $0.8<\mu<1.3$, OJ $>\mathrm{CJ}$; therefore, when consumers are not sensitive to the technical content of new products and there is competition between horizontal enterprises, cooperative $\mathrm{R} \& \mathrm{D}$ is better than independent $R \& D$. Independent $R \& D$ is better than cooperative $R \& D$ when the sensitivity coefficient of the new product's technical content increases and there is a cooperative relationship between horizontal enterprises.

Figure 4 indicates that with the increase in the sensitivity coefficient of new product technical content, the wholesale price will increase under each strategy. When $0<\mu<1.15$, $\mathrm{CL}>\mathrm{OJ}>\mathrm{OL}>\mathrm{CJ}$, the game equilibrium strategy of fully cooperative innovation is optimal; when $\mu>1.15$, $\mathrm{OJ}>\mathrm{CJ}>\mathrm{OL}>\mathrm{CL}$, the game equilibrium strategy of competition-cooperation innovation (collaboration-independent $R \& D$ ) is optimal.

Figure 5 demonstrates that as the sensitivity coefficient of new product technical content increases, the market price of each strategy also increases. In the case of $0<\mu<0.13$, $\mathrm{CL}>\mathrm{OJ}>\mathrm{OL}>\mathrm{CJ}$, cooperation is better than competition; when $\mu>0.13, \mathrm{OJ}>\mathrm{OL}>\mathrm{CJ}$, competition is better than cooperation.

Figure 6 shows that as the sensitivity coefficient of new product technical content increases, the total profit of the automobile manufacturer in the four game scenarios also increases. When $0<\mu<1.2, \mathrm{OJ}>\mathrm{OL}>\mathrm{CJ}$, the game equilibrium strategy of competition-cooperation innovation (competition-cooperative $\mathrm{R} \& \mathrm{D}$ ) is optimal; when $\mu>1.2$, a game equilibrium strategy of pure competitive innovation is optimal.

Figure 7 illustrates that in the four game scenarios, the profit accruing to the automobile dealer increases with the increase of the sensitivity coefficient of new product technical content, and $\mathrm{OJ}>\mathrm{CL}>\mathrm{OL}>\mathrm{CJ}$. When the sensitivity
TABLE 2: Comparison of game equilibrium profit.

\begin{tabular}{lcc}
\hline $\begin{array}{l}\text { Game equilibrium strategy of } \\
\text { technology innovation }\end{array}$ & $\pi_{\mathbf{M}}^{\text {total }}$ & $\pi_{\mathbf{R}}^{\text {total }}$ \\
\hline OL & 20 & 49.3 \\
CL & 33.5 & 68.5 \\
OJ & 43.5 & 32.2 \\
CJ & 55 & 50 \\
\hline
\end{tabular}

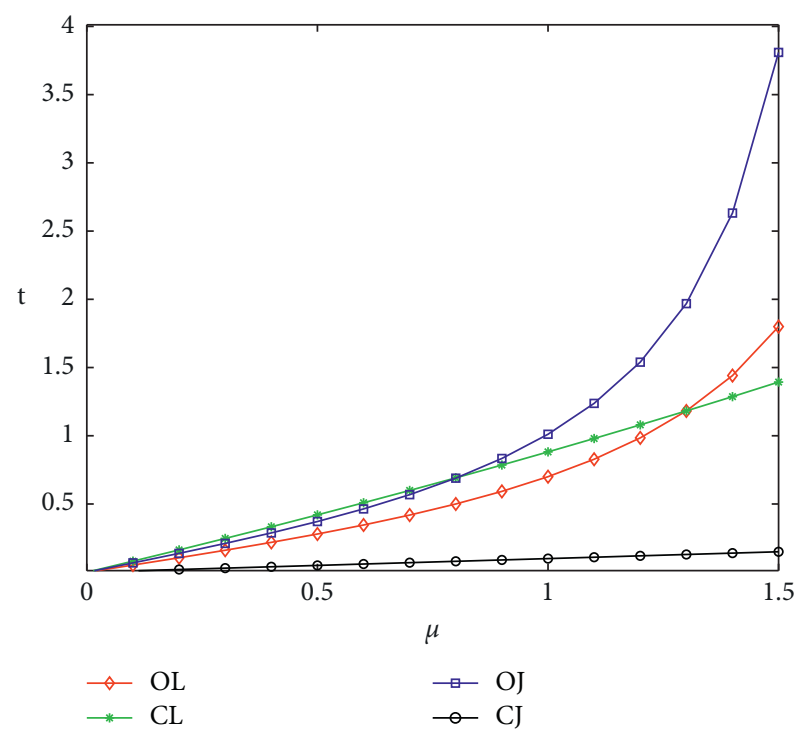

FIgURE 3: The influence of the sensitivity coefficient of the new product technical content on the new product technical content.

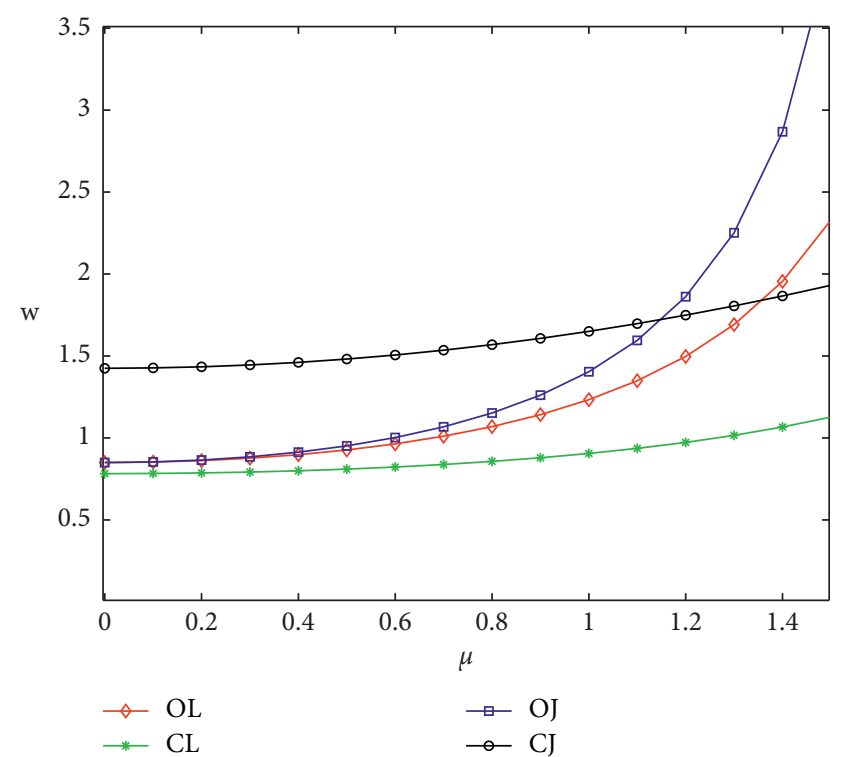

FIgURE 4: The influence of the sensitivity coefficient of the new product technical content on wholesale price.

coefficient of new product technical content is low $(0<\mu<0.5)$, the influences of competition and cooperation relationship and R\&D mode on an automobile dealer are not obvious; when the sensitivity coefficient of new product technical content is high $(\mu \geq 0.5)$, the influences of 


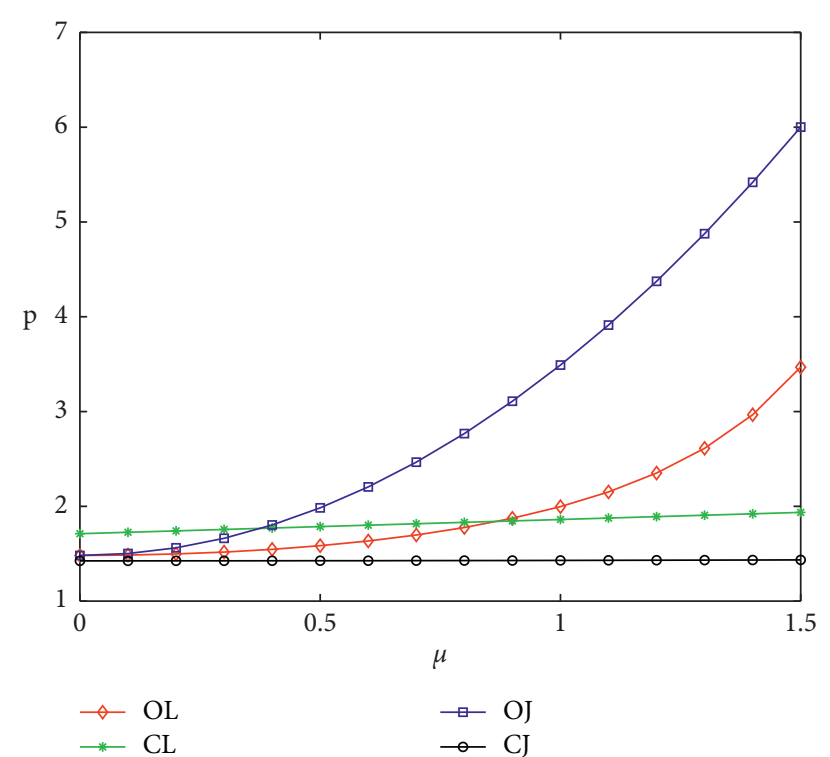

FIGURE 5: The influence of the sensitivity coefficient of the new product technical content on market sale.

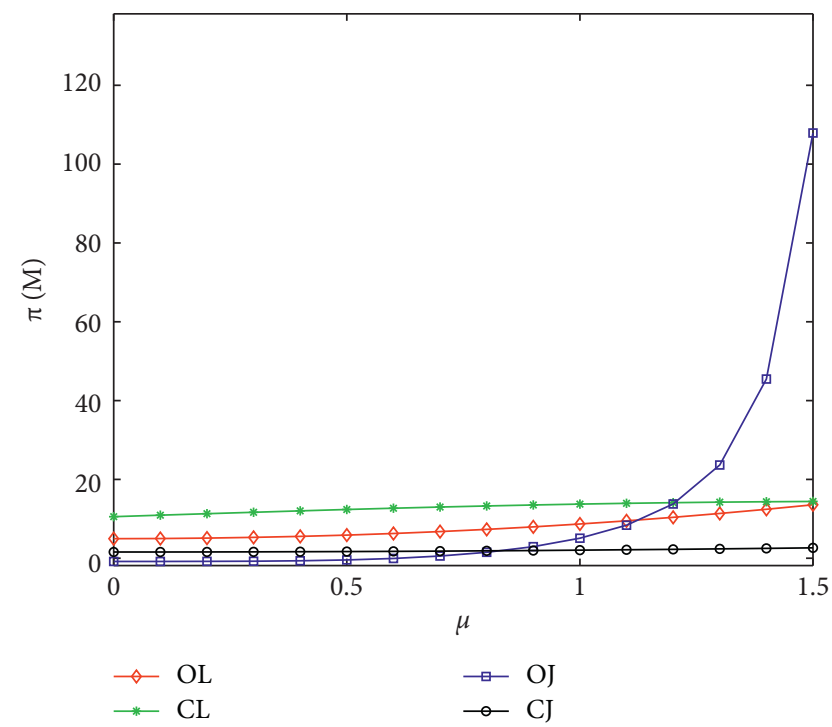

FIGURE 6: The influence of the sensitivity coefficient of the new product technical content on the total profit of automobile manufacturers.

competition and cooperation relationship and R\&D mode on automobile dealers are evident, and the degree of influence thereof increases with increasing sensitivity coefficient.

\subsection{Influence of New Product Technical Content on Equilib-} rium Solution. Here we describe an analysis of the influence of new product technical content on wholesale prices, market prices, demand, total profit accruing to the automobile manufacturers, and that of the automobile dealer. The results are shown in Figures 8-12.

Figure 8 shows that with the improvement of new product technical content, the wholesale price wholesale

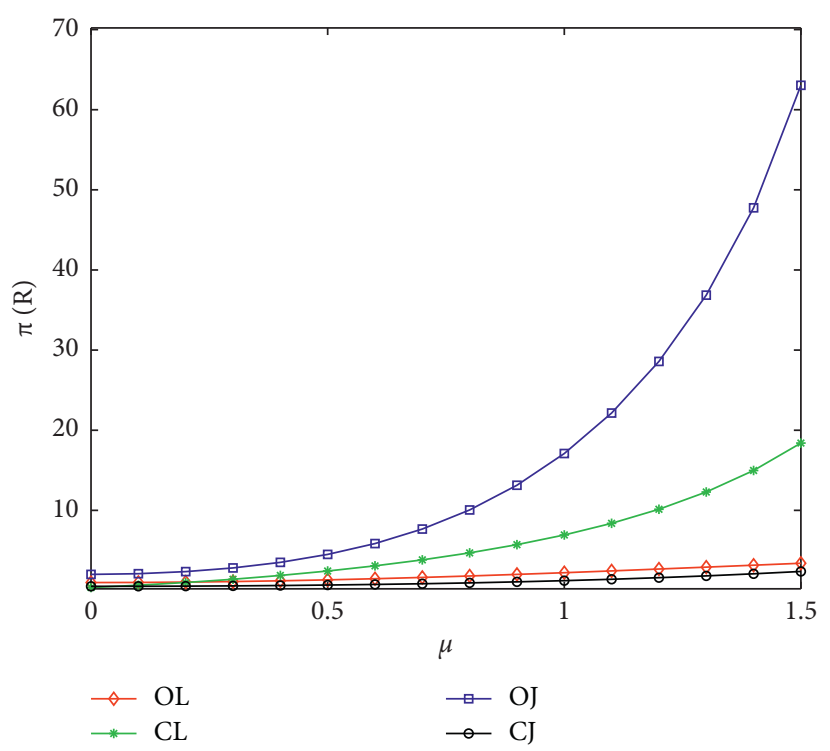

FIGURE 7: The influence of the sensitivity coefficient of the new product technical content on the profit accruing to the automobile dealer.

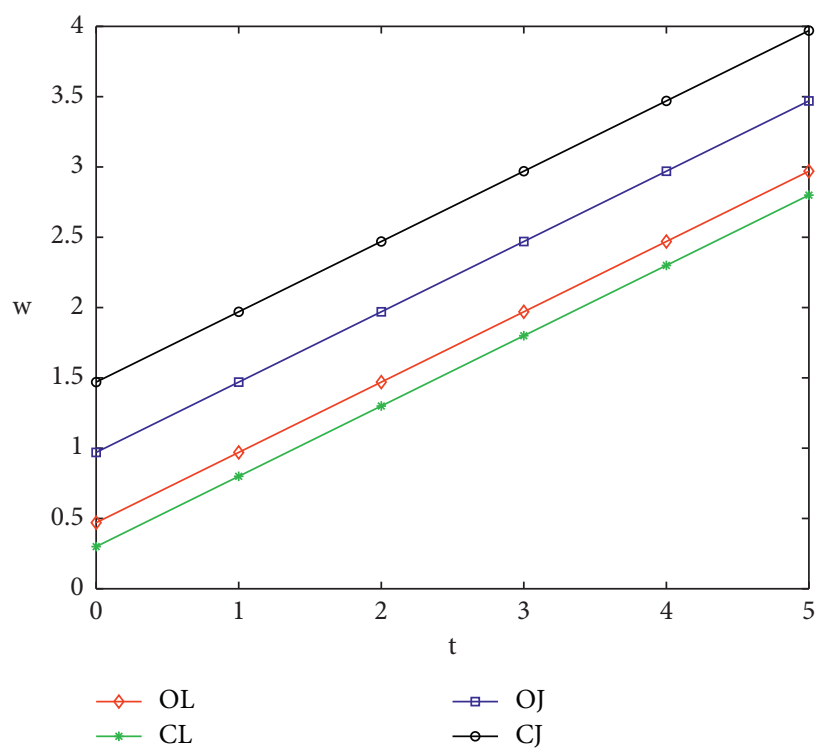

FIgURE 8: The influence of new product technical content on wholesale price.

price in every game equilibrium strategy also gradually improve, and $\mathrm{CJ}>\mathrm{OJ}>\mathrm{OL}>\mathrm{CL}$. It can be seen that when two companies have a cooperative relationship, cooperative $R \& D$ results in a higher wholesale price than independent $R \& D$ regardless of changes to the technical content of new products; when there is a competitive relationship between the two companies, independent $R \& D$ results in a higher wholesale price than cooperative R\&D.

Figure 9 illustrates that the market prices under the four game equilibrium strategies all increase with the increase in the technical content of new products, and the market prices under CJ conditions are significantly higher than when adopting other game strategies. In addition, when $0<t<4$, 


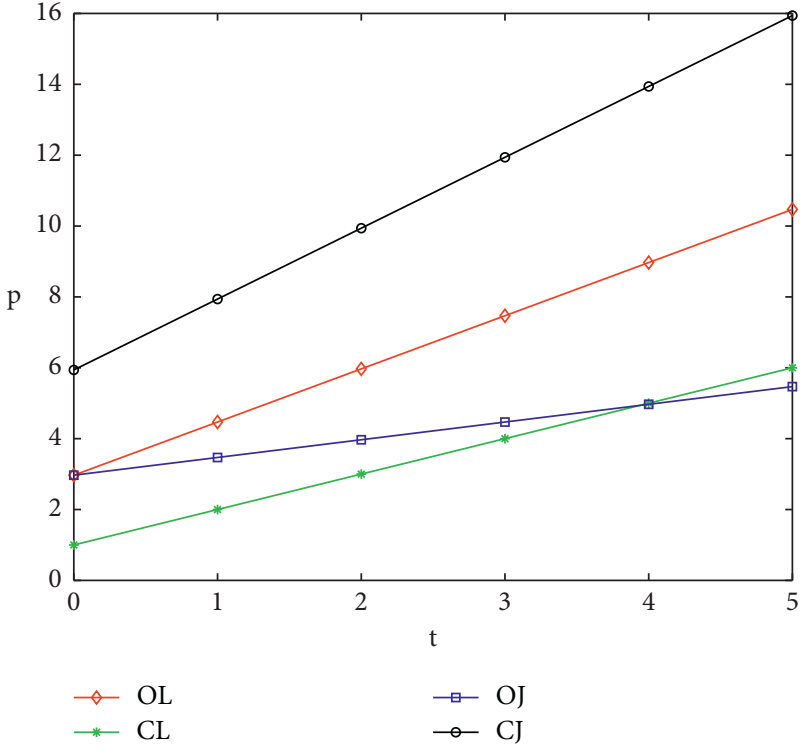

FIGURE 9: The influence of new product technical content on market price.

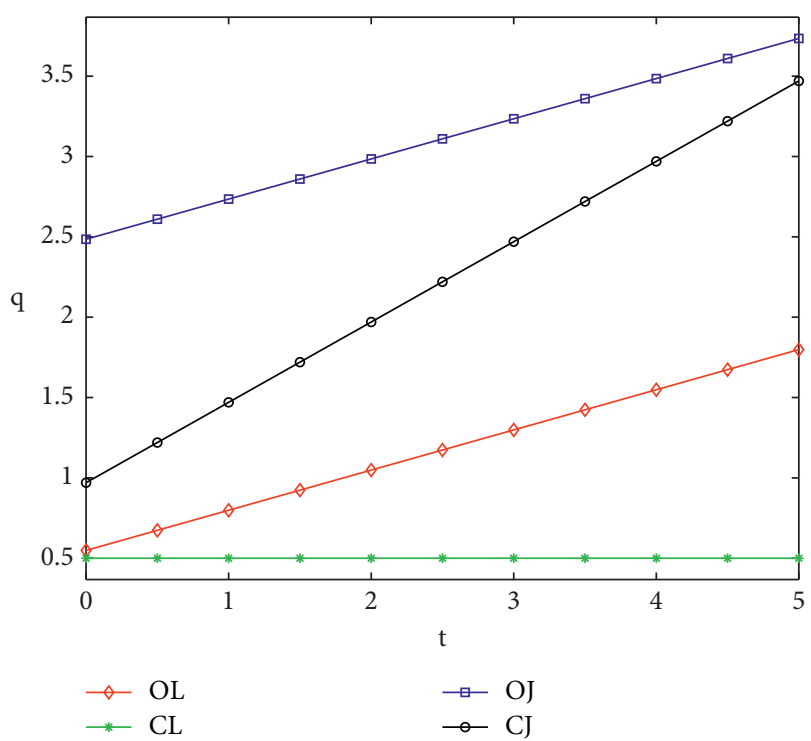

Figure 10: The influence of new product technical content on optimal demand.

$\mathrm{OJ}>\mathrm{CL}$, cooperation is always better than competition; when $t>4, \mathrm{OJ}>\mathrm{CL}$, and competition is better than cooperation.

Figure 10 shows that the technical content of new products is positively correlated with the demand of automobile manufacturers, with $\mathrm{OJ}>\mathrm{OL}$ and $\mathrm{CJ}>\mathrm{CL}$. This shows that a cooperative relationship is always better than a competitive relationship regardless of R\&D mode.

Figure 11 depicts that the technical content of new products is also positively correlated with the total profit of the automobile manufacturer, and CJ is the optimal strategy. This indicates that, if automobile manufacturers want to earn a greater total profit, they must improve the technical content of their products.

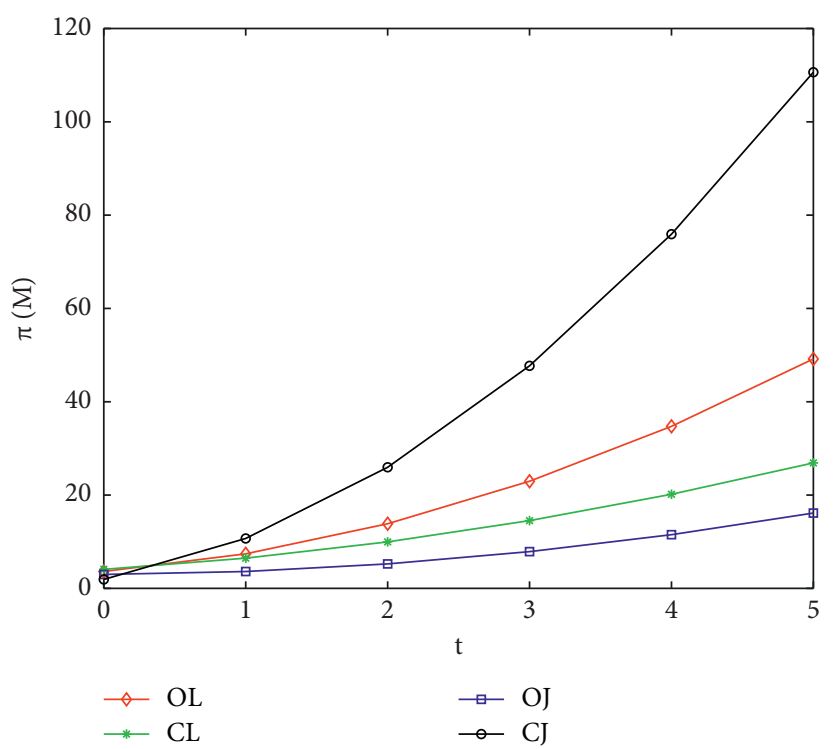

FIGURE 11: The influence of new product technical content on total profit of automobile manufacturers.

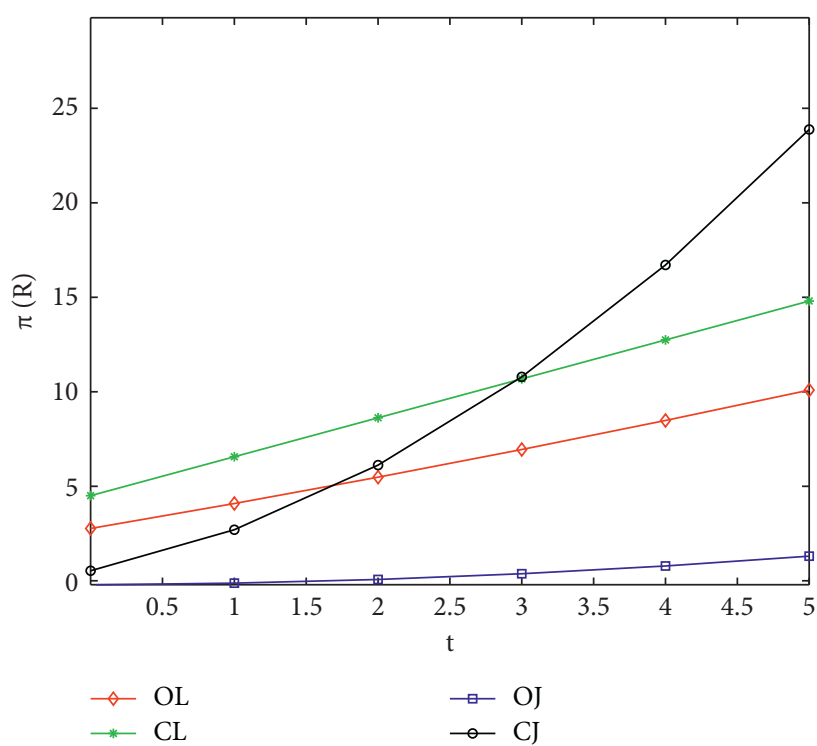

FIGURE 12: Influence of new product technical content on the profit accruing to an automobile dealer.

Figure 12 suggests that the improvement of technical content of the new product can enable automobile dealers to earn greater profits. In addition, when the technical content of the new product is relatively high $(t>2.96)$, the game equilibrium strategy of fully cooperative innovation is much better than the other three game situations.

5.4. Influence of Competitive Intensity on Equilibrium Solution. Herein, the influence of competitive intensity between two automobile manufacturers on the equilibrium solution of the supply chain is evaluated. The results are illustrated in Figures 13-17.

Figure 13 shows that, with the increase of competitive intensity, $\mathrm{CJ}>\mathrm{OJ}>\mathrm{OL}$, and $\mathrm{CL}$ first increases and then 


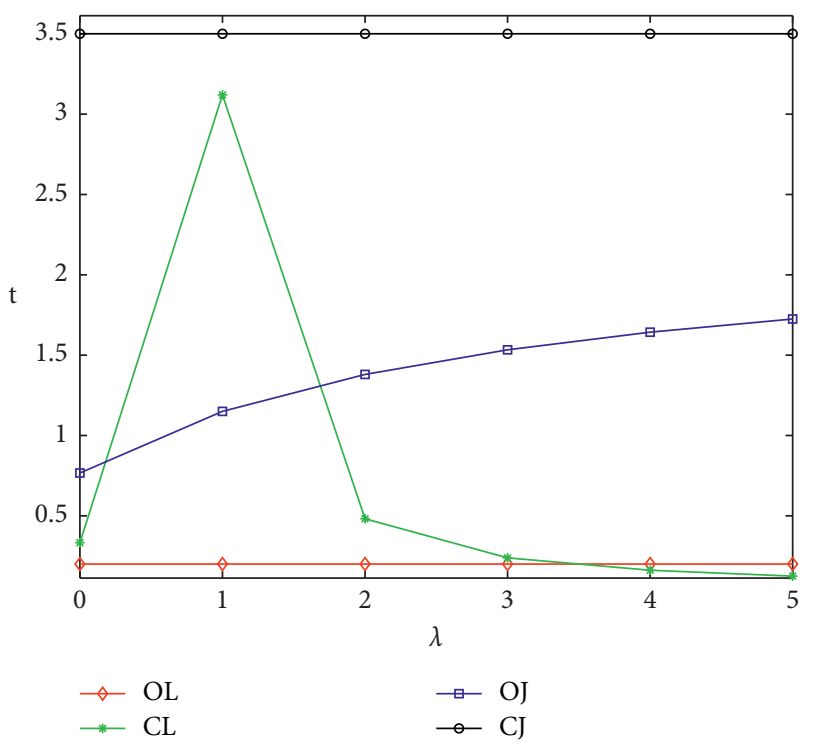

FIGURE 13: The influence of competitive intensity on new product technology content.

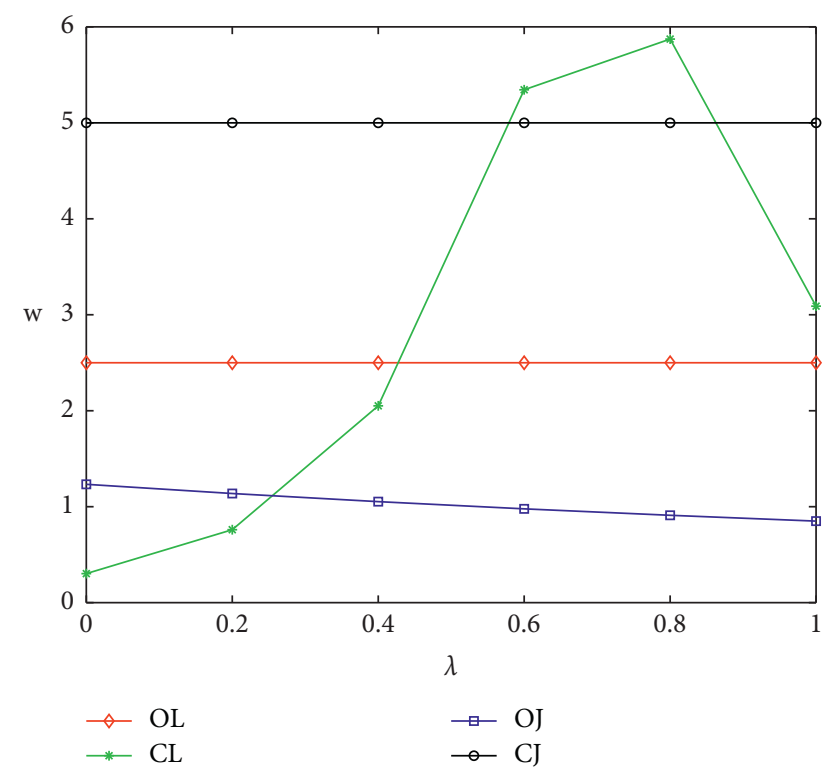

FIGURE 14: The influence of competitive intensity on wholesale price.

decreases. To improve the technical content of new products, the competitive intensity must be controlled within a reasonable range. Meanwhile, the technical content of new product in OL and CJ will not change with the increase in the intensity of competition but will increase in OJ.

Figure 14 illustrates that the competitive intensity does not affect the wholesale price of OL and CJ, and $\mathrm{CJ}>\mathrm{OL}>\mathrm{OJ}$, indicating that cooperative $\mathrm{R} \& \mathrm{D}$ is better than independent $\mathrm{R} \& \mathrm{D}$. In addition, when $0<\lambda<0.8$, the technical content of new products of CL increases with the competitive intensity.

Figure 15 shows that the competitive intensity does not affect the market price of CJ and OJ, while the market price

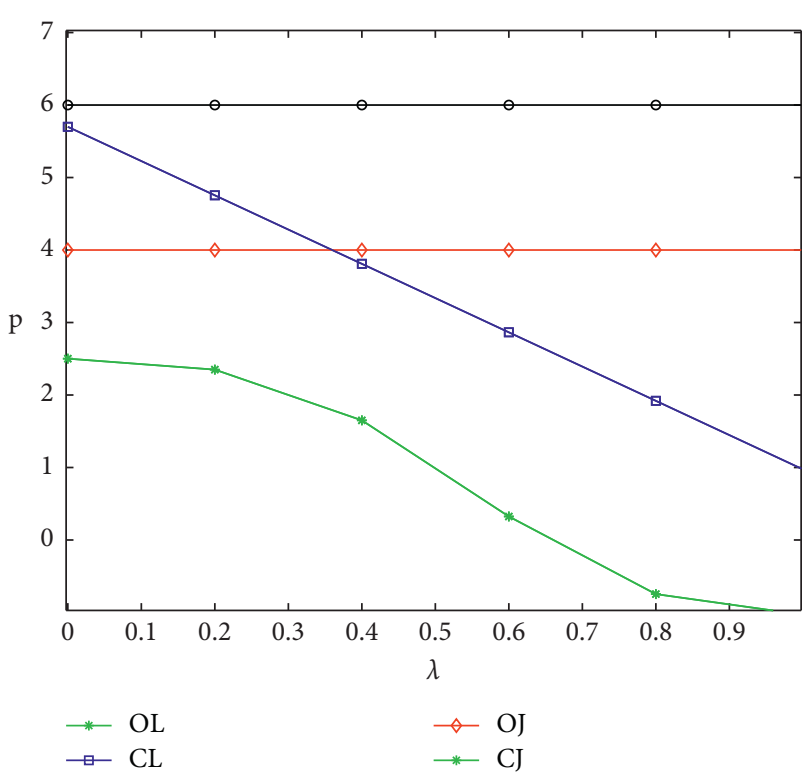

FIGURE 15: The influence of competitive intensity on market price.

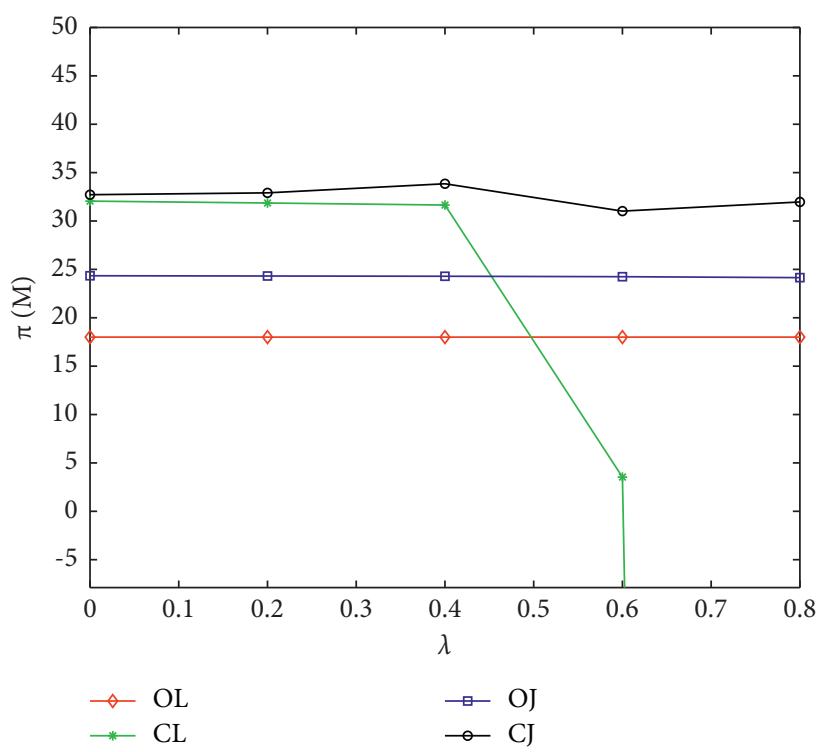

FIGURE 16: The influence of competitive intensity on total profit of automobile manufacturers.

of CL and OL decreases with increasing competitive intensity. When the competition is not fierce, $0<\lambda<0.36$, cooperative $R \& D$ is superior to independent $R \& D$; when $\lambda>0.36$ and the competition is increasingly fierce, independent $\mathrm{R} \& \mathrm{D}$ is superior to cooperative $\mathrm{R} \& \mathrm{D}$.

Figure 16 demonstrates that the competitive intensity does not affect the total profit of manufacturers under OJ and OL strategies. Whether the competition is fierce or not, the automobile dealer can obtain the highest profit under the CJ strategy. When $\lambda \geq 0.6$, the total profit of automobile manufacturers under a CL strategy decreases to zero, indicating that, when the competition is fierce, the $\mathrm{CL}$ strategy will reduce the profit earned by the automobile dealer. 


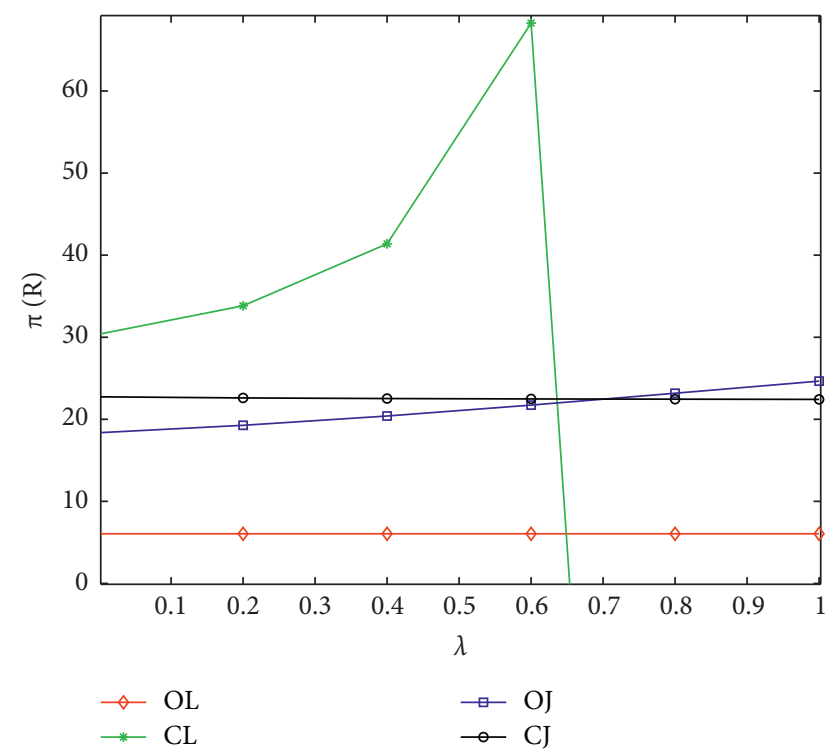

Figure 17: The influence of competitive intensity on the profit accruing to an automobile dealer.

Figure 17 depicts that as the competitive intensity increases, the profit of automobile dealer remains unchanged under the OL strategy, and increases under the OJ and CJ strategies, and first increases and then decreases under the CL strategy. In the case of $\lambda<0.6$, the automobile dealer can obtain the maximum profit under the CL strategy, and $\mathrm{CL}>\mathrm{CJ}>\mathrm{OJ}>\mathrm{OL}$, indicating that cooperative $\mathrm{R} \& \mathrm{D}$ is better than independent $\mathrm{R} \& \mathrm{D}$. When the competition is very fierce $(\lambda>0.6), \mathrm{OJ}>\mathrm{CJ}>\mathrm{OL}, \mathrm{OJ}$ is superior to OL.

\section{Conclusion}

The horizontal competition-cooperation game strategy of technological innovation in two-stage automobile cluster supply chain composed of duopoly of automobile manufacturers and a single automobile dealer is explored. According to the competition-cooperation relationship and R\&D mode of horizontal automobile manufacturers, four game models of technological innovation are constructed and used to analyse the equilibrium solution under different game situations. The main conclusions and recommendations are as follows:

(1) The game equilibrium strategy of fully cooperative innovation can maximise the technical content of new product, wholesale price, and total profit of automobile manufacturers but cannot maximise the profit to the automobile dealer. This is mainly because fully cooperative innovation can reduce repetitive $R \& D$ costs resulting in the highest wholesale price, thus bringing more profits to automobile manufacturers; however, for the automobile dealer, $\mathrm{OJ}$ is the optimal strategy. Therefore, to maximise the total profit of automobile manufacturers and dealer, cooperative R\&D mode should be selected to improve the degree of information sharing and share the R\&D costs.
(2) When the horizontal competition is not fierce and the consumption preference for technical content is weak, the OJ strategy will bring the maximum profit to the automobile dealer, but will reduce the profit of automobile manufacturers, and the profit of the manufacturer is the lowest among the four game strategies under OJ strategy; with the intensification of horizontal competition, automobile manufacturers will inevitably lower the wholesale price to seize the market, increasing the profit of the automobile dealer under the game equilibrium strategy of $\mathrm{OL}$ to a level above that accruing under the OJ strategy. In addition, it also suggests that automobile manufacturers should adopt a differentiation strategy to maintain certain differences of products when developing new products in horizontal cooperation, thus reducing the competitive intensity between the two products and obtain more profits.

(3) No matter how the competition and cooperation relationship and the $\mathrm{R} \& \mathrm{D}$ model change, the market demand, wholesale price, market sales price, and technical content of new products will increase with the increase of consumer preference for the new products' technical content, but the growth rate under each game equilibrium strategy is different, and is greatest under the OJ strategy. Therefore, channel members along the automotive supply chain will enhance the technical content of new products by increasing investment in new product $\mathrm{R} \& \mathrm{D}$ and accelerating technical innovation. In addition, market preference for technical content of automotive products can bring more potential benefits to supply chain channels. Supply chain decisionmakers should grasp the market opportunities brought by technical content preference to promote the benign development of the automotive supply chain.

\section{Data Availability}

The data used to support the findings of this study are available from the corresponding author upon request.

\section{Conflicts of Interest}

The authors declare no conflicts of interest.

\section{References}

[1] B. Du, Q. Liu, and G. Li, "Coordinating a Sustainable Innovation Supply Chain with Cooperative Investment Contract under Stackelberg Game," in Proceedings of the 2017 14th International Conference on Service Systems and Service Management (ICSSSM), June 2017.

[2] X. Lu, J. Wang, S. Yao, and L. I. Yan-xia, "Cloud service supply chain cooperation and technological innovation decision based on competition and cooperation game," Soft Science, vol. 32, no. 11, pp. 39-43, 2018.

[3] S. Yoon and S. Jeong, "Effects to implement the open-innovation coordinative strategies between manufacturer and 
retailer in reverse supply chain," Journal of Open Innovation Technology Market \& Complexity, vol. 3, no. 1, p. 2, 2017.

[4] J. Zhang, Zi Wang, and F. Yu, "Technological innovation of new products mode selection in longitudinal supply chain," Journal of Management, vol. 17, no. 170, pp. 82-84, 2020.

[5] C. Wang, "Research on the Income Distribution of Collaborative Innovation in the Supply Chain of SMEs Based on the Modified Shapley Value Method," Master Thesis of Hunan University, pp. 42-55, 2017.

[6] Z. Mu, Y. Zheng, and H. Sun, "Cooperative green technological innovation of an E-commerce sales channel in a twostage supply chain," Journal of Sustainability, vol. 13, no. 13, pp. 2-28, 2021.

[7] J. Wei and C. Wang, "Improving interaction mechanism of carbon reduction technology innovation between supply chain enterprises and government by means of differential game," Journal of Cleaner Production, vol. 296, Article ID 126578, 2021.

[8] Y. Li, S. Rong, and X. Hu, "Research on the influencing factors of the technological innovation capability of the automobile industry based on system dynamics," Journal of Industrial Technology Economy, vol. 36, no. 2, pp. 50-56, 2017.

[9] S. Li, Y. Zhang, and R. Feng, "Dynamic game analysis of technology diffusion and innovation performance: case study of China's automotive industry," Research Series on the Chinese Dream and China's Development Path, pp. 73-85, 2019.

[10] Y. Deng, “Agglomeration of technology innovation network of new energy automobile industry based on IoT and artificial intelligence," Journal of Ambient Intelligence and Humanized, 2021.

[11] W. Li, L. Dai, B. Guo, and S. Wu, "Game analysis of cooperation and innovation between upstream and downstream enterprises of new energy vehicles under the compound traction mechanism in the post-subsidy era," Journal of Soft Science, vol. 35, no. 1, pp. 81-88, 2021.

[12] H. Liu and J S. Feng, "Horizontal competition and cooperation game and pricing strategy of supply chain considering product greenness," Industrial Engineering and Management, vol. 22, no. 4, pp. 91-99, 2017.

[13] S. M. Seyedhosseini, S.-M. Hosseini-Motlagh, M. Johari, and M. Jazinaninejad, "Social price-sensitivity of demand for competitive supply chain coordination," Computers \& Industrial Engineering, vol. 135, pp. 1103-1126, 2019.

[14] Y. Hong and G. Naihan, "Analysis of Supplier Competitiveness in Supply Chain Profit Distribution from the Perspective of Quantity Supplied and Price Research Based on Cournot Model and Bertrand Model," International Conference on Strategic Management, pp. 22-27, 2019.

[15] T. Li, D. Yan, and S. Sui, "Research on the Complexity of Game Model about Recovery Pricing in Reverse Supply Chain Considering Fairness Concerns," Complexity, vol. 202013 pages, 2020.

[16] F. Mai, J. Zhang, and X. Sun, "Analysis of dynamic Cournot game in a coopetition supply chain," Discrete Dynamics in Nature and Society, vol. 2020, Article ID 4168395, 12 pages, 2020.

[17] R. Hu, C. Qi, and P. Yuan, "Game Analysis of optimal technical content in R\&D of duopoly enterprises with heterogeneous products," Scientific and technological progress and countermeasu-res, vol. 26, no. 17, pp. 82-84, 2009.

[18] H. Chu, "Research on Technology Content Promotion Mechanism of Medical Devices Based on Revenue Sharing Model," Master Thesis of Tianjin University, pp. 15-17, 2019.
[19] B. Jiang, J. Qin, S. Chen, and K. Lin, "Market demand orientation of technological innovation: a questionnaire analysis from consumer choice preference," Journal of Science and management, vol. 29, no. 1, pp. 20-25, 2019.

[20] M. Deng, "Evolutionary game analysis on technology innovation cooperation and $\mathrm{R} \& \mathrm{D}$ of Chinese petroleum enterprises," Journal of Chemical Industry Management, vol. 9, pp. 52-53, 2018. 